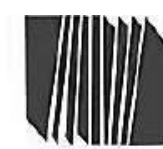

UNIVLRSIDADPEDAGOGICA EXPLR HALNTAL LIBCR TROO

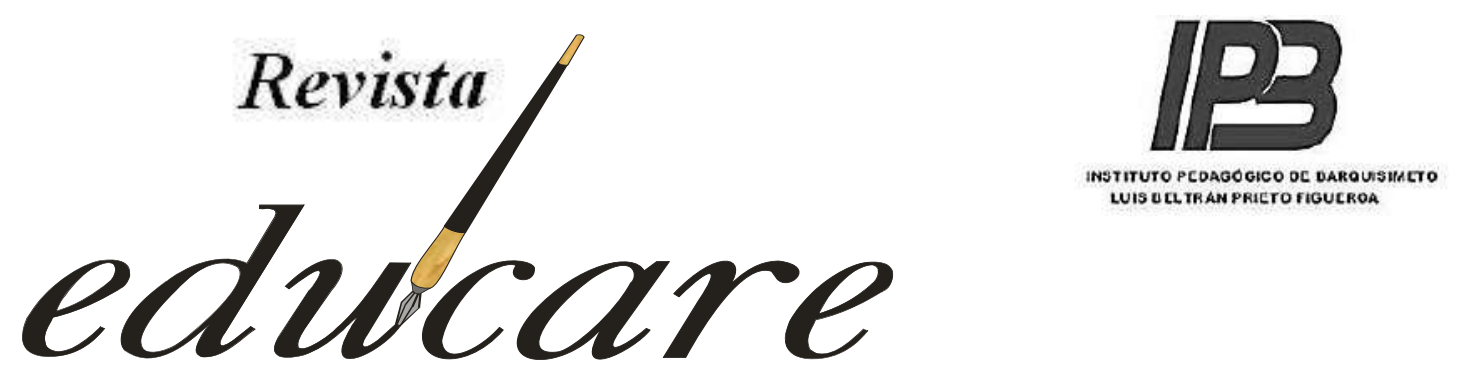

Órgano Divulgativo de la Subdirección de Investigación y Postgrado del Instituto Pedagógico de Barquisimeto "Luis Beltrán Prieto

Figueroa"

RARQUISUUEIO - EDO. LARA - VEMEZUELA

\title{
EL PENSAMIENTO DIDÁCTICO DEL DOCENTE DE EDUCACIÓN INICIAL COMO ELEMENTO REFLEXIVO DE LA PRÁCTICA PEDAGOGICA
}

THE TEACHING THOUGHT OF THE INITIAL EDUCATION TEACHER AS A REFLECTIVE ELEMENT OF THE PEDAGOGICAL PRACTICE

Elba Avila

UNIVERSIDAD PEDAGOGICA EXPERIMENTAL LIBERTADO UPEL 


\begin{tabular}{|c|c|}
\hline$\underline{\text { Revisión Documental }}$ & $\begin{array}{l}\text { Elba Ávila* } \\
\text { UPEL-IPB }\end{array}$ \\
\hline Recibido: 15-02-2016 & Aceptado: : 12-07-2016 \\
\hline ABSTRACT & RESUMEN \\
\hline $\begin{array}{l}\text { El presente artículo, se inscribe en la } \\
\text { modalidad documental, y tiene como objetivo } \\
\text { profundizar en los fundamentos teóricos } \\
\text { predominante del Pensamiento Didáctico y la } \\
\text { Práctica Pedagógica del Docente de } \\
\text { Educación Inicial. En este sentido, las ideas, } \\
\text { creencias, concepciones, opiniones, } \\
\text { principios y teorías implícitas de vida } \\
\text { profesional son importantes para poder } \\
\text { entender el quehacer didáctico del docente de } \\
\text { este nivel educativo; el mismo está } \\
\text { determinado por prácticas educativas muy } \\
\text { particulares, y enmarcada por momentos que } \\
\text { van desde la atención a los aspectos que } \\
\text { tienen que ver con las necesidades básicas del } \\
\text { niño hasta aquellas que impulsan la } \\
\text { creatividad, la exploración, la manipulación, } \\
\text { el desarrollo del lenguaje, la inteligencia y } \\
\text { todas las formas de expresión con el } \\
\text { propósito del que el éste se apropie de los } \\
\text { conocimientos. Para concluir, es oportuno } \\
\text { resaltar, que la práctica educativa orientada a } \\
\text { través de las teorías permiten que estas se } \\
\text { modifiquen en forma continua; ejerciendo un } \\
\text { influjo importante de manera tal que el } \\
\text { conocimiento teórico se ve sometido al } \\
\text { cambio al igual que el acto didáctico. }\end{array}$ & $\begin{array}{l}\text { This article is part of the documentary } \\
\text { modality and aims to delve into the theoretical } \\
\text { underpinnings of Didactic Thinking and the } \\
\text { Pedagogical Practice of the Initial Education } \\
\text { Teacher. In this sense, the ideas, beliefs, } \\
\text { conceptions, opinions, principles and implicit } \\
\text { theories of professional life are important to be } \\
\text { able to understand the didactic task of the } \\
\text { teacher of this educational level; The same is } \\
\text { determined by very particular educational } \\
\text { practices, and framed by moments ranging from } \\
\text { attention to aspects that have to do with the basic } \\
\text { needs of the child to those that drive creativity, } \\
\text { exploration, manipulation, } \\
\text { development, Intelligence and all forms of } \\
\text { expression for the purpose of which the latter } \\
\text { appropriates knowledge. To conclude, it is } \\
\text { opportune to point out that educational practice } \\
\text { oriented through theories allow them to be } \\
\text { modified continuously; Exerting an important } \\
\text { influence in such a way that theoretical } \\
\text { knowledge is subject to change as well as the } \\
\text { didactic act. }\end{array}$ \\
\hline $\begin{array}{l}\text { Descriptores: Pensamiento Didáctico, } \\
\text { Práctica Pedagógica, Educación Inicia }\end{array}$ & $\begin{array}{l}\text { Keywords:Didactic Thinking, Pedagogical } \\
\text { Practice, Initial Education }\end{array}$ \\
\hline
\end{tabular}

*Profesora adscrita al Programa de Educación Inicial de la Universidad Pedagógico Experimental Libertador del Instituto Pedagógico de Barquisimeto Venezuela. (UPEL-IPB) Especialista en tecnología aplicada a la educación, Coordinadora de la Línea de Investigación Saber Pedagógico del Profesional Docente de la Educación Infantil. Candidata a Doctor del Programa Interinstitucional del Doctorado en Educación PIDE. Email. Correo Electrónico: avilaelba@gmail.com 


\title{
INTRODUCCIÓN
}

\author{
Un verdadero educador es más artista que técnico, y \\ es más sabio que erudito. Hay demasiados técnicos \\ en educación y mucha capacitación en métodos y \\ disciplinas. Pero lo humano se lesha escapado. \\ Anónimo
}

En Venezuela y en la mayoría de los países del mundo, en los últimos años se han hecho propuestas importantes en materia educativa, generando una transformación y modernización curricular en cada uno de los niveles y modalidades del sistema educativo, con el propósito de dar respuesta a las exigencias de una sociedad dinámica encauzada por acelerados cambios culturales, políticos, económicos y científicos, con miras en construir un paradigma educativo cuyo núcleo de acción esté centrado en el ser humano como un ser social, capaz de responder y participar activamente en la transformación de la sociedad en la que vive.

Es de hacer notar, que esta transformación y modernización curricular permite la transición de modelos educativo centrados en la enseñanza y en contenidos programáticos, a un modelo orientado en el estudiante, como actor y protagonista de su propio proceso de aprendizaje; todo ello en consonancia con las tendencias filosóficas actuales que destaca la importancia de la educación para la vida, a través de la formación integral del educando con énfasis en los valores para lograr propiciar la colaboración, el amor al trabajo, la convivencia, la paz y la armonía entre las personas. (Ministerio de Educación Cultura y Deporte, 2005), conduciendo de esta manera, a la educación como un continuo de desarrollo humano que se ejecuta a través de los procesos de enseñanza y aprendizaje.

Sin duda alguna, estos cambios a nivel curricular, han impuestos importantes desafíos especialmente a los docentes, vistos que ellos independientemente del nivel educativo en que laboren, constituyen los actores privilegiados para la concreción del proceso de enseñanza y aprendizaje y la transformación social.

De esta perspectiva, es necesario que los docentes que laboran en contexto educativos de atención a la primera infancia, desde su pensamiento didáctico, reflexionen en su práctica pedagógica, y asuman compromisos, en la que de forma efectiva atiendan las necesidades de aprendizajes de los estudiantes, propiciando en ellos los conocimientos 
necesarios que le permitan afrontar los cambios sociales y políticos que emergen en su entorno inmediato.

El compromiso que ha de asumir el docente y así lo plantea la Organización de las Naciones Unidas para la Educación, la Ciencia y la Cultura UNESCO (2012) contempla en contribuir al logro de adquisición de conocimientos y competencias elementales, promover la comprensión y el respeto de los derechos humanos, la inclusión, la equidad y la diversidad cultural, e impulsar el deseo y la capacidad de aprender a lo largo de toda la vida.

Es de exaltar, que el éxito o el fracaso de toda la transformación curricular dependen en gran medida de la actitud del docente en la interpretación y adaptación que le dé a los cambios propuesto, pues, son ellos los llamados a ser mediadores del proceso de aprendizaje. En relación a lo expresado, Elliot (1997) señala que el docente es y debe ser un generador de conocimientos, cuando reflexiona y teoriza desde su práctica, reconstruyéndola y resignificándola; cuando decide ser un consumidor de conocimientos producidos por otros o ser un productor de conocimientos y teorías a partir de la reflexión desde la práctica educativa.

Es por ello que este artículo pretende realizar un entramado entre el pensamiento didáctico del docente de Educación Inicial y la reflexión desde su práctica pedagógica tomando en consideración aspectos teóricos relevantes que le permitan reedificar desde una mirada crítica su quehacer didáctico cotidiano para dar respuestas al cómo, para qué y por qué, de su acción en la complejidad rutinaria de los ambientes de aprendizaje en que se desenvuelve.

Por otro lado este artículo se inserta en la Línea de investigación "Saber Pedagógico del Profesional Docente de Educación Infantil”, del Instituto Pedagógico de Barquisimeto contribuyendo de esta manera al enriquecimiento del saber en este campo de acción.

\section{EL DOCENTE DE EDUCACIÓN INICIAL Y SU DIDÁCTICA}

En Venezuela, a partir del año 2005 se pone en práctica de manera oficial un nuevo diseño curricular para el nivel de a Educación Inicial con una concepción educativa fundamentada en el desarrollo del ser humano; es un currículo participativo, flexible y 
contextualizado que atienda la diversidad social y cultural en una sociedad democrática, participativa, multiétnica y pluricultural; y está sustentado bajo los preceptos constitucionales de la República Bolivariana de Venezuela en la que se define a la educación como un derecho humano y un deber social para el desarrollo de la persona, desde una perspectiva de transformación social-humanista orientada a la formación de una cultura ciudadana.

En este nuevo currículo se suscribe al docente dentro del paradigma constructivista, en cuya tendencia se concibe como una persona práctica, reflexiva y transformadora, con características referidas a un profesional que contribuye a su formación desde la acción educativa, investigador de la enseñanza y desarrollador de su práctica de una manera contextualizada, proponiendo actividades para la construcción activa de los saberes.

Además se proyecta como un profesional que actúa en función de un perfil polivalente, abierto, dinámico, reflexivo, crítico, investigador que incorpora en su hacer didáctico habilidades, conocimientos y actitudes para formular, diseñar y desarrollar estrategias y programas de intervención educativa en contextos socioeducativos y culturalmente cambiantes. (Ministerio de Educación y Deporte. Documento Bases Curriculares 2005).

De igual manera este perfil del docente de Educación Inicial se suscribe dentro de los cuatro pilares del conocimiento planteado por la UNESCO (1996) los cuales apuntan hacia una formación integral profundamente humana que reúna tanto aspectos personales, afectivos, actitudinales, intelectuales y habilidades como la relación con los demás. Estos pilares son: aprender a hacer, aprender a conocer, aprender a convivir y aprender a ser; los mismos están asociados a los distintos roles y competencias del docente requeridos en la cotidianidad de la acción pedagógica.

Sobre la base de lo expuesto, la enseñanza bajo el enfoque constructivista se ve como un proceso a través del cual se ayuda, se apoya y se dirige al estudiante en la construcción del conocimiento. En referencia, Freire (1997), señala que enseñar entonces no es transferir conocimientos sino crear las posibilidades de su producción o de su construcción. Aunado a este pensamiento, Ugas (2013) exalta la labor del docente dentro del enfoque constructivista señalando que "la función del docente no es trasmitir contenidos y/o conocimientos, lo pertinente es organizar los saberes, un maestro es aquel 
que tiene la capacidad de poder inventar nuevas funciones de su labor y reinventar su desempeño todo los días" (p33).

Desde estas perspectivas, el docente de Educación Inicial, está llamado a considerar en su hacer didáctico la estructura conceptual de cada niño, sus ideas y preconceptos que posee, y es precisamente desde estos primeros esquemas conceptuales que el estudiante va a proporcionar sus principales significados también llamados conocimientos intuitivos o ingenuos hasta llegar a conocimientos más complejos formales o científicos.

Sin duda alguna, la didáctica del Nivel de Educación Inicial debe enmarcarseen el paradigma constructivista cuyo campo de acción se despliega en generar experiencias de aprendizaje a niños desde los 0 años de edad hasta los 6 o cuando ingresen al primer grado de Educación Básica.

En tal sentido, la acción didáctica del docente debe estar centrada en suscitar experiencias de aprendizaje que permitan a los niños, fortalecer sus potencialidades para un desarrollo pleno y armónico, para que sean autónomos, creativos, dignos, capaces de construir conocimientos, de comunicarse, participar en su entorno libre y creativamente, cooperar y convivir con tolerancia y respeto por los demás, todo esto bajo una perspectiva mediadora constructivista. Establecido de esta manera en el Documento Bases Curriculares de Educación Inicial (MED 2005)

Cabe destacar, que el docente que centra su práctica pedagógica en el paradigma constructivista sus esfuerzos se concentran en sus estudiantes, en conocer cómo aprenden y para qué aprenden, en generar en ellos cambios conceptuales significativos a través de una interacción que contempla a los estudiantes, los contenido y al contexto, todo esto a través de una mediación educativa.

Ante esta situación, se asume que la calidad educativa, en el Nivel Inicial depende en alto grado del docente en su rol de mediador, por ello, es necesario que este profesional tenga una preparación profunda sobre el desarrollo del infante 0 a 6 años, de las formas como aprende, de sus derechos, sus intereses, sus potencialidades y de su entorno familiar y comunitario, con el propósito de generar aprendizajes, conjuntamente con la interacción social y cultura.

Lo ideal es una didáctica más centrada en el que aprende y no en el que enseña, un docente con esta visión, incrementa su profesión pero debe darse la oportunidad para 
reflexionar en lo que hace, y como lo hace, sobre las exigencias que la sociedad le demanda a su quehacer. En este sentido Ruay (2010) señala que el acto reflexivo del docente se entrecruza las creencias, preocupaciones, ideas, contextos y los desafíos propios de la educación. Es preciso señalar que esta reflexión está situada en un contexto social y temporal determinado, por tanto el educador para el siglo XXI tiene sus propios derroteros, desde donde ha de abarcar, al menos, tres grandes áreas de desarrollo como lo refiere referido:

1.- El desarrollo personal, orientado a la autoestima y auto imagen de sí mismo, para enfrentar los procesos de cambio que se van produciendo en la sociedad y en la institución escolar.

2.- El desarrollo social. Aprender a trabajar con otros, a formar equipos y establecer relaciones empáticas.

3.- El desarrollo profesional, que implica nuevas formas de trabajo, diseño de proyectos innovadores con un sentido cada vez mayor de "visión pedagógica".

De este modo el papel del docente cobra un sentido más amplio que va desde lo personal hasta lo social y profesional, donde este último, es parte de una racionalidad del conocimiento, que se demanda como desafío a la escuela de hoy, segúnDelors (1996) en el informe presentado a la (UNESCO) por la Comisión Internacional sobre Educación para el siglo XXI el docente debe orientar su quehacer en función a cuatro grandes pilares: “Aprender a aprender, Aprender a hacer, Aprender a ser, Aprender a convivir y colaborar con los demás". Y a esto se le agrega una serie de valores que se consideran fundamentales en una sociedad cambiante donde el docente debe profundizar en su práctica pedagógica, como lo son: la solidaridad, el respeto y la responsabilidad.

Es de destacar que la didáctica de la Educación Inicial es muy activa, movida por una serie de momentos que van desde la atención a los aspectos que tienen que ver con las necesidades básicas hasta aquellas que impulsan la creatividad, la exploración, la manipulación, el desarrollo del lenguaje, y todas las formas de expresión bajo un ambiente de aprendizaje seguro, dinámico y flexible, todo esto en el marco de una intencionalidad pedagógica. Para ello el docente debe lograr la interacción del niño con sus pares a través de una mediación que procure, el aprendizaje activo, participativo y que este se transfiera a sus contextos funcionales y de vida cotidiana 
Visto de esta manera, se demanda de un docente que supere el memorismo, la metodología tradicional de los ambientes educativos y así lograr un aprendizaje significativo, más integrador, comprensivo y autónomo, una construcción de conocimientos en forma pertinente y creativa así como lo señala Méndez de Garagozzo (2007), un docente que logre articular en su práctica pedagógica todos aquellos conocimientos y teorías adquiridas durante su formación profesional. Y esto se concreta en el acto reflexivo no solo del conocer, sino en el hacer didáctico.

Es importante que el docente de Educación Inicial asuma con responsabilidad la didáctica de este nivel, que piense en ella como un acto reflexivo, pues no solo va a orientar y a motivar al niño a construir el conocimiento, sino también le va a ayudar a potenciar todas sus capacidades cognitivas, estéticas, sociales y afectivas, además, esto le permite a él como docente trascender no solo en su conocer si no en su hacer didáctico para relacionar los hechos, las situaciones, los problemas con el mundo circundante del estudiante.

Esta actitud de ir más allá de lo que el currículo dicta y así lo plantea López y Basto (2010) le da la oportunidad al docente para establecer conexiones, suscitar dilemas, promover dudas, crear posibilidades, generar espacios, a su vez que suscita la reflexión de su didáctica.

Por otro lado le ayudará a presentar las situaciones de aprendizaje de forma interesante, de manera que este se implique activa y emocionalmente en la tarea donde el niño perciba que lo que aprende en realidad es significativo para su existencia, y quien le enseña es alguien en el que puede creer y confiar.

Por consiguiente, la didáctica del nivel inicial es muy especial, comprometida a través de la mediación educativa a instaurar bases sólidas para la formación de la personalidad del niño; en tal sentido, el docente en su práctica pedagógica debe procurar aprendizajes significativos para asegurar que los conocimientos adquiridos en los espacios educativos puedan ser utilizados en circunstancias de la vida cotidiana.

Para lograr este tipo de aprendizaje, la metodología a utilizar por el docente debe tomar en cuenta los intereses, necesidades y potencialidades de los niños así como sus conocimientos previos obtenidos en su entorno social y cultural.

De conformidad con lo expresado, Ugas (2013), hace referencia a que el acto didáctico debe ser un acto de amor, como una pedagogía de sentimientos que se constituye 
en una necesidad teórica y práctica la cual debe estar dirigida a la triada "conocer, pensar, reflexionar" todo esto para conformar una dinámica que no se debe limitar al uso de contenidos programáticos, sino a una pedagogía activa, que le permita al niño desarrollar su autonomía y conocer su entorno en función de sus necesidades, destrezas y potencialidades.

Es por ello que en la didáctica de este nivel educativo, se concibe el rol del docente como mediador de experiencias de aprendizaje, entendiendo la mediación como el proceso mediante el cual se produce una interacción social entre dos o más personas que cooperan en una actividad conjunta, con el propósito de producir un conocimiento, (Coll 1986).

De igual manera López y Basto (ob.cit) refieren que mediar significa intervenir entre los seres y la realidad para facilitar los procesos de aprendizaje; es decir, el docente se convierte en el mediador por excelencia, pues no solo va a orientar y a motivar al estudiante a construir el conocimiento, sino también va a ayudarle a potenciar todas sus capacidades cognitivas, estéticas, sociales y afectivas.

Tébar citado por López y Basto (ob.cit) propone tres principios básicos inherentes al proceso mediador: intencionalidad y reciprocidad, trascendencia y significado. La mediación es una interacción intencionada, por ello supone reciprocidad: enseñar y aprender son un mismo proceso. Los procesos comunicativos humanos son la plataforma de este principio, pues aquí entra en juego el lenguaje del cuerpo: el gesto, la mirada, el tono de voz, la expresividad que va a denotar y connotar la intencionalidad del mediador y su capacidad comunicativa y motivacional.

Es de exaltar, que el proceso de mediación que realiza el docente de educación inicial no solo debe poseer los principios antes referidos sino debe hacerlos concreto en los ambientes de aprendizaje, y estos a su vez deben transcender a la familia y a la comunidad donde se vea involucrado la parte social y cultural, de tal manera que el niño pueda logra un aprendizaje que tenga conexión con su entono real y que sean significativos, esto quiere decir entonces que labor educativa del docente debe estar orientada a vencer el memorismo, la metodología tradicional de los ambientes educativos.

\section{PENSAMIENTO DIDÁCTICO DEL DOCENTE DE EDUCACIÓN INICIAL}

El pensamiento didáctico en forma genera se concibe como todas aquellas reflexiones 
que el docente realiza en y durante su acción pedagógica; es un acto de madurez que le ayuda a comprender su quehacer pedagógico, y la complejidad de la acción educativa.

El proceso de pensamiento según Ruiz (2003) representan el conjunto de las cogniciones internas del sujeto que determinan su hacer; comprende las actitudes, valores, emociones, expectativas, habilidades, creencias, emociones y conocimiento, que explican un determinado comportamiento humano.

Se puede considerar lo referido a una primicia que marca la pauta del pensamiento didáctico, pues en este acto reflexivo tiende a reflejarse aspectos objetivos (teorías, conocimientos) como subjetivos (emociones, sentimientos, creencias, valores) que de una $\mathrm{u}$ otra manera orientan al docente para entender las diferentes situaciones de enseñanza y de aprendizaje.

Es así como se puede entender al pensamiento didáctico en palabras de Figueroa y Páez (2009), como el conjunto de ideas, creencias, concepciones, opiniones, principios y teorías implícitas de vida y profesional que posee el docente sobre su quehacer didáctico durante la práctica pedagógica. De igual manera las autoras antes referidas destacan que el pensamiento didáctico es un hecho complejo, y lo asocian con el acto de aprender a reflexionar en torno a diversas acciones.

Por otro, lado Díaz (2004) señalan que el pensamiento didáctico o pensamiento pedagógico constituyen un marco que “...integra un conjunto de teorías implícitas, creencias, expectativas, nociones y valores mediante los cuales el profesor significa, interpreta, decide y actúa en sus actividades educativas" (p.136). Estas expresiones de ambos autores las podemos visualizar en la ilustración que a continuación se presenta:

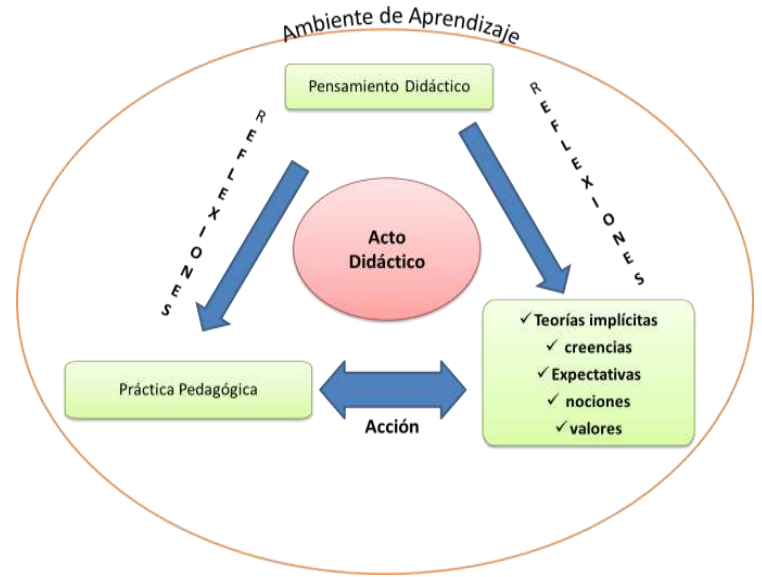

Grafico $\mathbf{N}^{\circ} 1$ Ilustración del concepto de Pensamiento Didáctico 
En esta ilustración se perciben el ambiente de aprendizaje como un campo de acción, y en este se encuentran estrechamente interrelacionadas por tres dimensiones en la que se da el acto didáctico como son: el pensamiento, las teorías implícitas, y la práctica pedagógica, las cuales en conjunto con la reflexión le permiten al docente tomar decisiones y hacer de su acto pedagógico una acción provista de sentido.

Centrando la mirada en el docente de Educación Inicial, es necesario que en su accionar didáctico exista sensibilidad y consciencia ante las teorías que impregnan su práctica pedagógica, esto le va a permitir realizar una didáctica acorde con las exigencias de su entorno, centrada en el niño en sus potencialidades y necesidades.

En tal sentido, se puede decir que el acto didáctico requiere que el docente de este nivel educativo sea reflexivo ante la complejidad de este proceso, puesto que cuando él piensa lo que va a hacer, refleja la realidad de lo que está dentro de su estructura mental es decir sus conocimientos; y para ello, requiere de la organización previa de las ideas que están en su estructura cognitiva, de tal manera de que sus pensamiento implícito no se sobrepongan sobre el conocimiento explicito, y así evitar generar una desvinculación entre la teoría y la práctica.

Con respecto a lo anterior, considero que es preciso señalar que tantos las creencias como los prejuicios de los docentes, tienden a ser construidos ante y durante la formación académica, y prevalecen durante su ejercicio profesional, y en muchas ocasiones tienden a revelarse solo por intuición y no por la razón. Sin embargo como dice Monarca (2011) "Hace falta una racionalidad docente que sea capaz de estar poderosamente presente en su acción; es decir, que ofrezca la unidad necesaria entre el pensamiento, el conocimiento y la acción en un contexto específico" (p.106).

Ahora bien, es importante que el docente que labora desde los espacios educativos de la Educación de Inicial considere que reflexionar en su didáctica le va a permitir una mejor comprensión del cómo y el porqué de su práctica educativa, además que le ayudará mejorar y significar su accionar en el aula, a innovarla inventarla y reinventarla; así como también enfrentar de una mejor manera su profesión, y adaptarse con mayor facilidad a los cambios que pudiesen producirse en el ámbito en el cual se desenvuelve.

De igual manera, cuando el docente reflexiona en su hacer didáctico, tiene una mayor concreción de la realidad educativa, de los intereses y necesidades de sus 
estudiantes a su vez que lo lleva a realizar una práctica contextualizada y sobre todo organizada. Ese pensamiento didáctico el cual está ligado a la reflexión la conduce a la emisión de juicios, a la resolución de problemas y a la toma de decisiones de una manera efectiva.

En este sentido podemos apreciar que el pensamiento didáctico como una acción recursiva, se reflexiona en la práctica donde intervienen aspectos subjetivos entre ellas las creencias las emociones los valores, que en conjunto con los aspectos objetivos como las teorías y los conocimientos, forman un entramado con el propósito de generar nuevas teorías, nuevas formas de accionar sobre el hecho educativo y permite tomar decisiones, dar soluciones, y mejorar la acción didáctica.

Esa reflexión del docente de Educación Inicial en el quehacer educativo, en el contexto, las idea, y las experiencias, le permiten fijar su atención en el niño, en sus conocimientos previos, en sus imágenes del mundo y en sus creencias, para propiciar estrategias que posibiliten la satisfacción de las necesidades e intereses tanto individuales y grupales; es la mejor manera de contribuir en su formación integral.

\section{EL DOCENTE DE EDUCACIÓN INICIAL Y LA PRÁCTICA PROFESIONAL}

Para muchos autores del contexto educativo, la educación es un arte porque pone en práctica a las teorías y las técnicas educativas en la emergen nuevas experiencias para reformar o ratificar la teoría inicial. Es una manera de encontrar a la teoría y la practicas en una fuerte relación; haciendo el desarrollo de la educación cada vez más sólido.

En este sentido Mallart (2002) señala que el valor de la práctica profesional es muy grande y que ésta se halla omnipresente tanto en las actividades de los alumnos como en las de los profesores: "aprendemos por experiencia pero también enseñamos por experiencia. El peligro es la rutina y la solución puede estar en la reflexión individual y colectiva" (p.6).

Por consiguiente, se puede decir que la práctica pedagógica del docente en el contexto de la Educación Inicial es el indicador que da indicios sobre la realidad del ambiente de aprendizaje, es precisamente en ese accionar del docente donde se le da vida a la teoría y se contrasta con la realidad, bien sea para enriquecerla o generar de ella 
nuevas teorías, sin obviar elementos importantes como los recursos, actividades y estrategias todas ellas enmarcada en una planificación con sentido globalizador de los aprendizajes donde a través de una buena mediación se enriquece la acción educativa.

Desde esta perspectiva, Losso, (2006), expresa que la práctica del docente es la que hace evidente el saber durante sus proceso de mediación, y este saber, que adquiere el docente durante la práctica le da la condición de pedagogo, que en términos cotidiano se considera el saber enseñar; es decir, las formas de mediación institucional del saber social.

Es así como la práctica pedagógica del docente de Educación Inicial, como acto recursivo, tiene la particularidad de considerar en el niño todos sus aprendizajes previos producto de la interacción social para generar nuevos aprendizajes significativos y de esta manera asegurar que los nuevos conocimientos adquiridos por él puedan ser utilizados en circunstancias de su vida cotidiana.

En este sentido, para Latorre (2003), la práctica pedagógica no es solo una acción observable, un hacer verificable ni solo un conjunto de creencias, visiones y percepciones, un pensar y sentir de los profesores, es la integración de las teorías educativas como elementos que guían la práctica. Señala el autor que una práctica pedagógica reflexiva, investigadora y transformadora, contrarresta a una práctica guiada por concepciones y creencias producto de la tradición cultural que permanecen implícitas.

Al hacer énfasis en este planteamiento, Ugas (2003) refiere que "La práctica pedagógica no es una técnica cuyas reglas fijas regulan acciones para conseguir metas, tampoco está determinada por leyes eternas. El razonamiento de la acción conduce a comprender que un saber no se compone de reglas sino de principios aplicados”. (p. 14).

En referencia a lo que señala el autor, el principio de acción de la práctica pedagógica, del docente de Educación Inicial, está orientada por la mediación educativa, la cual es entendida como el proceso mediante el cual se produce una interacción social, con el propósito de producir conocimientos. Es decir, que la práctica pedagógica de este nivel educativo se considera un proceso dinámico que parte de la necesidad de una mediación educativa activa, planificada e intencional, con el objeto de garantizar que el niño construya experiencias de aprendizaje, es un proceso de reflexión, que propicia la toma de decisiones y lo considera como sujeto y actor de su proceso de aprendizaje. 
Se infiere de esta manera que la practica pedagógica de este nivel educativo bajo la premisa de la medicación considera aspectos fundamentales, como son: la posición constructivista del conocimiento, la globalización de los aprendizajes, el aprendizaje significativo y las estrategias de aula, familia y comunidad. Una pedagogía bajo este punto de vista orienta su accionar tomando en cuenta los intereses y potencialidades de los niños y niñas, su forma de aprender, sus conocimientos previos, así como su relación con los demás.

Desde esta concepción didáctica, emerge un docente autónomo, que piensa en la educación a través de la reflexión sobre lo que hace en las aulas de clase; que toma decisiones con base a la interpretación de la realidad, y crea situaciones nuevas a partir de los problemas, de la práctica cotidiana con la finalidad de mejorar o transformar su actuación didáctica.

Esta perspectiva, constituye el punto de partida para fortalecer la figura del docente como crítico y competente para enfrentar los retos pedagógicos que se presentan en el día a día, la idea es que desde la práctica el docente no solamente consuma los conocimientos sino que también genere nuevos conocimiento. Esto le permitirá reflexionar sobre la práctica y adoptar una posición crítica frente a la misma; pues el cambio educativo es posible cuando el profesor cuestiona de manera propositiva su práctica pedagógica.

Al respecto, García (2007) sostiene que el conocimiento práctico no es un saber de la acción o para la acción sino en y desde la acción, el cual no se configura como acontecimiento teórico previo que se aplica automáticamente a la acción, sino como un saber hacer que se va decantando en el mismo ejercicio didáctico, pero influenciado por la reflexión del docente.

En tal caso para Bedoya (1998)la reflexión de la práctica pedagógica permite que el docente reedifique desde una mirada crítica su quehacer didáctico cotidiano, es por ello, que es necesario volver la mirada sobre lo que individual y colectivamente se construye en los espacios de aprendizaje, esto no solo permite reflexionar en la práctica pedagógica, sino que al mismo tiempo permite la integración pedagógica con las ciencias como una propuesta para superar la dicotomía pedagogía-ciencias de la educación. 


\section{MODELOS PEDAGÓGICOS QUE ORIENTAN LA PRÁCTICA DEL DOCENTE DE EDUCACIÓN INICIAL}

Como se ha planteado al principio de este artículo, la didáctica de la educación inicial desde los preceptos curriculares debe estar enmarcada en el paradigma constructivista, en cuyos rasgos generales coloca al niño en el centro de la acción educativa haciéndolo protagonista en la apropiación de los aprendizaje, donde el docente funge como mediador para aproximarlo al conocimiento desde la inmediatez de su contexto.

Sin embargo, podemos encontrar en las aulas de educación inicial prácticas pedagógicas enmarcadas por diferentes modelos pedagógicos, desde los que buscan enseñar mediante la repetición y la memorización de los contenidos, hasta aquellos que pretenden la construcción de conocimientos como resultado del desarrollo de ciertas estrategias pedagógicas, incluida la creación de las llamadas situaciones de aprendizaje o proyectos didácticos de aprendizajes.

Según Flórez (1994) un modelo es la imagen o representación del conjunto de relaciones que definen un fenómeno, con miras a su mejor entendimiento. De acuerdo con esta definición se puede deducir que un modelo debe estar enmarcado dentro de una estructura teórica donde se apoya y obtiene su aprobación.

Igualmente el autor antes referido afirma que los modelos pedagógicos representan formas particulares de interrelación entre los parámetros pedagógicos. Estos parámetros pedagógicos se encuentran inmersos de acuerdo a lo que establece el autor a la concepción del ser humano que se desea formar en torno a las exigencias de la sociedad, en líneas gruesas es lo que establece el currículo educativo.

Por su parte De Zubiría (1994), hace referencia de que el cuaderno de un niño, los textos que se usan, un tablero con anotaciones, la forma de disponer el salón o simplemente el mapa o el recurso didáctico utilizado, dicen mucho más de los enfoques pedagógicos de lo que aparentemente podría pensarse.

Son en realidad la huella inocultable de la concepción pedagógica. Se entiende, que en la anterior idea las prácticas cotidianas del aula de clase son las manifestaciones materiales de un modelo pedagógico que de manera implícita se encuentra en las acciones didácticas de los maestros. Es decir, que el docente posee un discurso teórico-implícito que da soporte a sus prácticas de enseñanza. 
Ahora bien al volver la mirada hacia la Educación Inicial nos encontramos con grandes precursores que sentaron las bases de los sistemas de la educación infantil, cuyos pensamientos han permanecido vigentes a lo largo de los siglos hasta los tiempos actuales y que de una u manera orientan la actuación didáctica del docente de este nivel.

Entre ellos se destaca a Pestalozzi (1786-1827) y Froebel (1782-1852), ellos impulsaron la reforma de la educación, y propusieron modelos para conducir la enseñanza a partir de los mecanismos naturales que emplea el niño para apropiarse del aprendizaje. Para Pestalozzi de acuerdo a Rubio (2012) Su principal objetivo fue adaptar el método de enseñanza al desarrollo natural del niño, quien debía aprender a través de sus propias experiencias.

Estas ideas fueron tomadas por Montessori (1870-1952) y Dewey (1859-1952)pero dándole un sustento desde la psicología para entender la personalidad del niño y a su vez haciendo uso de metodología científica, como la observaciones detalladas del infante, para tomar decisiones sobre la forma más pertinente de conducir la enseñanza y obtener el resultado esperado científicos para descifrarlo. Para Rubio (ob.cit) los principios que rigen el método Montessori se resumen en autonomía, independencia, iniciativa, desarrollo de la voluntad, capacidad para elegir y autodisciplina.

A pesar de los aportes de estos precursores, la acción didáctica del docente dentro del aula de educación inicial la encortamos enmarcada en dos grandes paradigmas el conductismo y constructivismo. Para el conductismo, lo más importante es el resultado y los elementos observables del aprendizaje. Este paradigma su interés primordial es la conducta sus objetivos están centrados en describirla, predecirla y controlarla.

Por otro lado, la educación con enfoque constructivista se encauza en fortalecer el aprendizaje del estudiante mediante la construcción de significado en un ambiente que propicia la indagación. Cuyo propósito es colocar al niño frente a conflictos cognitivos que le permitan hacer uso de los procesos de pensamiento como la interpretación el análisis que le permitan desarrollar, construir y transformar nuevos significado a partir de experiencias vividas.

Este marco paradigmático permite entender desde el contexto de la Educación Inicial los modelos pedagógicos en que el docente de este nivel se apoya para consolidar los procesos de enseñanza y aprendizaje. 
A propósito de lo expresado se considera en forma de síntesis la clasificación de los modelos pedagógicos a criterios de Flórez (Ob.cit)

1.- Modelo pedagógico Tradicional: Desde este modelo se concibe la enseñanza bajo un esquema autoritario con el objeto de formar el carácter. La visualiza al alumno como un receptor y a los docentes como un modelo de autoridad y ejecutor de la práctica, mediante métodos de aprendizaje academicista.

2.-Modelo Transmisionista Conductista: Se promueve el moldeamiento de la conducta productiva de los sujetos e cuanto a la adquisición de conocimientos, códigos impersonales, destrezas y competencias configurándolos bajo un esquema de conducta observable que se corresponde con el desarrollo intelectual del individuo. El método que utiliza es el de la fijación y control de objetivos instruccionales los cuales son reforzados con precisión.

3.-Modelo Romántico Pedagógico: el creador de este método es Rousseau y el el se sostiene que hay que preservar la interioridad del niño tomándola como eje de la educación para que aflore y manifieste las habilidades naturales en un ambiente escolar flexible. Para ello el maestro debe desprenderse del autoritarismo y la rigidez de contenidos para convertirse en un promotor de la expresión libre.

4.-Modelos Desarrollista Pedagógico o Cognitivo (constructivista): Los precursores de este modelo son Dewey y Piaget, y está fundamentada en la necesidad de promover el desarrollo intelectual del individuo, el maestro es el encargado de propiciar las experiencias que desencadenan el acceso a las estructuras cognitivas superiores.

5.- La Pedagogía Socialista o Socio-cognitiva: Propone el desarrollo máximo y multifacético de las capacidades e intereses del individuo, los impulsores de este modelo son Makarenko y Freile y en él se sostiene que el desarrollo del individuo está determinado por la sociedad como el colectivo unificado en cuanto a lo productivo y educativo, todo ello en función del desarrollo espiritual, así como del conocimiento pedagógico multifacético y politécnico, considerando el contenido de las prácticas y los fundamentos que la soportan.

En este modelo, la relación del docente con el alumno es dialógica y el primero juega el rol de figura crítica que invita a la reflexión mediante el cuestionamiento permanente. Privilegia el trabajo en grupo y estimula la crítica mutua de modo que los estudiantes 
puedan mejorar su trabajo y apoyarse mutuamente, comprometiéndose colectivamente en la solución de problemas de interés social.

En función de los modelos pedagógicos antes descritos se infiere que el docente de educación inicial nada más por el hecho de estar inmerso en esta era posmoderna y globalizada, determinada por la transición, la diversidad y el incremento de la tecnología, donde se vislumbran nuevos escenarios para el aprendizaje, debe ampliar su mirada no solo para verse a sí mismo en el modo de enseñar, sino que debe reflexionar para comprender al niño en su forma de aprender y de apropiarse de los conocimientos. Este hecho, de acuerdo a lo que expresa Vilera (2005), cambia toda la ordenación disciplinante del pensamiento educativo prevaleciente en el transcurrir histórico de la modernidad, e implica la comprensión de visiones transformadoras en toda la labor de la enseñanza. Esto se traduce en nuevos desafíos los cuales le imputan retos inminentes a la educación, y por ende al docente en cuanto a su formación y el desarrollo profesional.

Aunado a esto, Amaro de Chacín (2006), señala que los tiempos actuales están reclamando un docente reflexivo como un agente transformador, en vista de que la revisión de las concepciones sustentadas del docente revelan una estructura conceptual marcadamente tradicional, poco clara e incoherente con la acción docente profesional; hay una tendencia en los docentes hacia el saber-hacer y escasamente hacia la reflexión de su propia práctica educativa.

Esto es cierto, en el sentido de que una adecuada acción docente favorece el aprendizaje, pero hay mucho más. En el fondo, la enseñanza implica un vínculo especial con el saber enseñar, con procesos didácticos organizados por el docente. Así, la enseñanza o acción pedagógica no puede consistir en un pase de información desde el docente hacia el alumno, sino que debe entenderse como la construcción de una serie de situaciones de aprendizaje que tienden a incidir sobre el proceso mismo.

\section{REFLEXIÓN FINAL}

Sin duda alguna, la sociedad demanda a un docente que desde la Educación Inicial se sienta comprometido, un docente eficaz caracterizado como un profesional que demuestre competencias, generador de cambios, polivalente, reflexivo de su hacer didáctico, 
investigador y promotor de soluciones, pensador crítico, con alto dominio de saberes, y contenidos pedagógicos, propios de su ámbito de enseñanza, que estimule y facilite los aprendizajes, al apropiarse de su rol no en términos de enseñar sino de lograr que el niño aprenda.

Sin embargo, desde mi reflexión considero que es necesario que el docente de educación tenga más rasgos humanos que entienda y valorice su profesión, que se sienta digno de serlo, que en ese reflexionar sobre su acción pedagógica realice una ruptura en el axioma "si el maestro enseña, el alumno debe aprender" pues esto solo induce al memorismo, esto implica replantear la labor de la enseñanza, de una nueva manera de concebir los procesos educativos, con una visión diferente en la formación profesional docente, la cual debe estar inspirada ahora en unas dimensiones epistemológicas donde abundan diversas formas de saber y, por ende, de aprender.

A manera de conclusión y en consideración a la temática seleccionada, considero importante que el docente haga una pausa en su hacer didáctico, para reflexionar en ese rol transcendental que la sociedad le ha encomendado, realmente propiciar experiencias de aprendizaje a estudiante de 0 a 6 años, es un reto muy complejo, sin embrago, el acto reflexivo del docente de su práctica diaria le va a permitir evaluar y co-evaluar sus aciertos y desaciertos didácticos así como sus debilidades y fortalezas, además que es una forma de contribuir desde la enseñanza haciendo uso de estrategias cognitivas, metacognitivas y motivacionales a producir el saber más que consumirlo, resolver problemas más que acumular la información. En suma contribuir a aprender a aprender de manera permanente a lo largo de la vida y en diferentes situaciones y contextos.

\section{REFERENCIAS}

Amaro de Chacín, R. (2006). Investigación didáctica y procesos de reflexión en el aula. Caracas: Ediciones Secretaría general UC.

Bedoya, J. (1998). Pedagogía: ¿Enseñar a Pensar? “[Documento en línea] Disponible:http://www.scielo.org.ve/scielo.php?script=sci_nlinks\&ref=1695509\&pid=S 1011-2251200600010000500003\&lng=es [Consulta 2013 marzo 10]

Coll, C. (1986). El marco Curricular e una escuela renovada. Madrid: MC y Editorial Popular S.A. 
Delors, J. (1996). Informe a la UNESCO de la Comisión sobre Educación para el siglo XXI. La educación encierra un tesoro. Madrid: Santillana. Ediciones UNESCO.

De Zubira, J. (1994) Tratado de Pedagogía Conceptual: Los modelos Pedagógicos. Santafé de Bogotá: Fundación Merani. Fondo de Publicaciones Bernardo Herrera Merino

Díaz, F. (2004) La Evaluación de la Docencia en la Universidad. Ed. UNAM, México.

Elliot, J. (1997). La Investigación- Acción en Educación. Ediciones Morata. Madrid.

Figueroa, N y Páez, H. (2009). Pensamiento didáctico del docente Universitario. Redalyc, [Revista en Línea] Disponible en: http://www.redalyc.org/articulo.oa?id=18411970006. [Consulta: 2015 febrero 12]

Flórez Ochoa, R. Hacia una pedagogía del conocimiento Santafé de Bogotá: McGraw-Hill, 1994. p. 60.

Freire, P. (1997). Pedagogía de la autonomía. México: Siglo XXI.

García, F. (2007) El profesorado y el conocimiento un relación compleja. Pamplona: Ediciones de la Universidad de Granada. https://dialnet.unirioja.es/descarga/articulo/23671.pdf [Consulta 2014 abril 23]

Latorre, A. (2003) Investigación-Acción, conocer y Cambiar la Práctica Educativa. Editorial Graó, Barcelona España

López, B. y Basto, S. (2010). Desde las teorías implícitas a la docencia como práctica reflexiva. [Revista en Línea]Disponible en: http://educacionyeducadores.unisabana.edu.co/index.php/eye/article/view/1699/2258[Con sulta: 2015 Noviembre 22]

Losso, M. (2006). Identidad del trabajo docente en el proceso de formación. Buenos Aires: Editorial Miño.

Mallart, J. (2002): “Didáctica: del currículum a las estrategias de aprendizaje”.

Méndez de Garagozzo, A. (2007). La Complejidad de los saberes haceres docentes desde la rutina a la cotidianidad. Visión del ser que construye el saber y el saber Hacer. Primera Edición. Editorial Excelencia Creativa. Barquisimeto- Venezuela.

Ministerio de Educación, Cultura y Deportes. Viceministerio de Asuntos Educativos. Dirección de Educación Preescolar (2005). Currículo Básico Nacional del Nivel de Educación Inicial. Caracas.

Monarca. H. (2011) Pensamiento Didáctico [Documento en Línea] Disponible en https://dialnet.unirioja.es/descarga/articulo/3653746.pdf [Consulta: 2015 Mayo 18] 
Ruay, R. (2010) El rol de docente en el contexto actual. [Revista en Línea] de Desarrollo y competencia de (REDEC) Disponible http://redec.utalca.cl/index.php/redec/article/view/53 [Consulta: 2015 Noviembre 22]

Rubio, M (2012) Modelos pedagógicos y competencias para la enseñanza en derechos humanos [Documento digital adobe acrobat] Disponible sin conexión [consultado 2016 enero 18]

Ruiz, C (2003) Pensamiento del docente, estrategia instruccional y resultados educacionales en una sociedad en transición [Documento en Línea] Disponible en http://www.ucv.ve/fileadmin/user_upload/sadpro/Documentos/docencia_vol4_n1_2003/8_ art._5_Carlos_Ruiz.pdf [Consulta: 2014 Julio 15]

Ugas, G. (2003). Del acto pedagógico al acontecimiento educativo. San Cristóbal:

Ugas, G. (2013) del acto de conocer al discurso que lo narra. Una Problemática Epistemológica. Lito Formas San Cristóbal estado Táchira. Venezuela.

UNESCO. (2012). Reunión Mundial sobre la Educación para Todos. (21-23 de noviembre) París

Vilera, A. (2005) La labor educativa en la sociedad del siglo XXI: Revista de Teoría y Didáctica de las Ciencias Sociales. Mérida-Venezuela [Revista en Línea].Disponiblehttp://www.saber.ula.ve/bitstream/123456789/24018/2/articulo6.pdf[ consulta 2015 Noviembre 22] 